\title{
DESLOCAMENTO DE ADJETIVOS NO SINTAGMA NOMINAL DO PORTUGUÊS
}

\author{
Afrânio da Silva Garcia (UERJ; ABRAFIL) \\ danafra@globo.com
}

\section{Introdução}

A ideia do presente trabalho surgiu a partir da leitura do excelente artigo da professora Miriam Lemle, intitulado A ordem dos adjetivos no sintagma nominal em inglês e português: implicações para a teoria gramatical, no qual ela explica, de maneira brilhante, as razões gramaticais e de discurso que determinam o tipo de correspondência entre as ordenações de adjetivos no português e no inglês.

$\mathrm{O}$ artigo da professora Miriam Lemle não nos explica, nem a autora a isso se propôs, os motivos que levam à anteposição de um adjetivo normalmente posposto ou, inversamente, à posposição de um adjetivo comumente anteposto num sintagma nominal constituído de um único adjetivo e um só substantivo, nem as regras que determinam tal variação.

Para obter maior clareza na apresentação, dividi o trabalho em cinco partes: na primeira, faço observações gerais sobre determinados conceitos que irei usar; na segunda, apresento as regras e tendências que norteiam a colocação dos adjetivos no português; em seguida, apresento os casos de anteposição do adjetivo e tento determinar suas causas; na quarta, exemplifico casos de posposição do adjetivo e procuro definir seus motivos; por último, mostro as conclusões a que cheguei, tentando esquematizá-las na forma de regras gerais de colocação dos adjetivos no português.

O corpus deste trabalho constitui-se, basicamente, de revistasem-quadrinhos infantis, revistas eróticas, revista "Cláudia" e de letras de músicas populares, por considerar este tipo de literatura mais fiel à fala coloquial do que a literatura erudita e artística. Além disso, utilizei-me do corpus da professora Miriam Lemle em seu artigo, de material visto em sala de aula e de artigos de jornal.

Quanto à importância do meu trabalho, considero-o de utilidade para os estudiosos de linguística ou de língua portuguesa, por 
fornecer uma base para a questão mais geral da ordem vocabular do português e suas razões, constituindo mais um estudo linguístico de natureza semântica, de que andamos carentes, e, ainda, por facilitar a explicação da ordem dos adjetivos nas classes de redação ou de sintaxe.

Quanto à notação, como só existe um tipo de adjetivo que não admite deslocamento, a notação com asterisco $(*)$, que indica sentença agramatical, será pouquíssimo usada. Em seu lugar, usarei um ponto de interrogação (?) antes das sentenças que forem muito estranhas e um ponto de exclamação (!) antes das que forem apenas um pouco estranhas.

\section{Observações preliminares}

No desenvolvimento deste traba1ho, explicarei certos casos de mudança na ordem do adjetivo dentro do sintagma nominal a partir de certos conceitos e definições. Como alguns dos leitores podem desconhecer tais conceitos, apresentarei aqui uma visão geral deles, seguida de esclarecimentos quanto às notações dos exemplos.

\subsection{Encapsulação e hiponímia}

Encapsulação indica uma relação de inclusão de significado do tipo significado de A contém significado de B, como em socar e punho e assassino e perverso, porque para se socar é preciso usar os punhos e para alguém ser assassino é necessário que seja perverso (ao menos, no nosso sistema de valores atual). Diríamos, então, que punho e perverso estão encapsulados, respectivamente, em socar e assassino.

Hiponímia, por sua vez, indica uma relação de significado assim como significado de A é um tipo de significado de B, como em ave e animal e samambaia e vegetal. Diríamos, portanto, que ave e samambaia são hipônimos, respectivamente, de animal e vegetal. 


\subsection{Sintagmas definidos e sintagmas indefinidos}

É importante, antes de tudo, distinguir sintagma nominal definido da noção geral de artigo definido, visto que nem todo SN definido requer artigo definido.

1) Esse curso foi muito proveitoso.

2) Sebastião Votre foi o melhor professor que eu tive neste semestre.

3) Minha namorada se chama Tânia.

Nesses três exemplos, o SN em itálico é definido, embora não apareça artigo definido. Mas se SN definido não é aquele em que aparece artigo definido, como saber quando um $\mathrm{SN}$ é definido?

Sintagma nominal definido seria todo aquele que apresentasse um conjunto ou um subconjunto de elementos em contraste com outros conjuntos ou subconjuntos da mesma espécie ( $S N$ definido por conjunto) ou um elemento (indivíduo ou grupo) de um conjunto em contraste com os demais elementos desse conjunto ( $S N$ definido por elemento). Não se deve confundir contraste, como é usado aqui, com a noção de contraste estabelecida por Creider, que só serve para SNs definidos por elemento de um conjunto.

4) O homem é o lobo do homem. (SN definido por conjunto)

5) O homem moderno é angustiado. (SN definido por subconjunto)

6) Aquele homem é perigoso. ( $\mathrm{SN}$ definido por elemento)

7) Aqueles homens são perigosos. (SN definido por grupo)

Sintagmas nominais indefinidos, ao contrário, são aqueles que representam um conjunto, subconjunto ou elemento indiferenciado dos demais conjuntos, subconjuntos ou elementos da mesma espécie.

8)Tenho televisão em minha casa.

9) Comprei um casaco.

Nesses exemplos, podemos ver que os $S N$ s indefinidos podem ou não vir com artigo indefinido. 


\subsection{Qualificação e contraste}

A distinção entre qualificação e contraste é importantíssima não só para o estudo da colocação do adjetivo no sintagma nominal, como também para o estudo da própria gramática portuguesa como um todo. Essa distinção, grosso modo equivalente àquela que se faz entre as orações adjetivas explicativas e restritivas, se aplica não apenas aos adjetivos, como aos substantivos, pronomes, numerais etc.

Qualificação seria a atribuição de uma qualidade, propriedade, aparência etc. a um determinado, atribuição essa que funcionaria como uma informação a mais sobre o determinado em questão.

10) Aquele garoto que vive dizendo que somos deselegantes e feios?

11) Vou torcer o gordo pescoço do sargento Tainha.

É importante notar que os adjetivos dos exemplos acima não isolam o referente determinado de outros da mesma espécie, isto é, deselegantes, feios e gordo não servem para distinguir os determinados nós e pescoço de outras pessoas ou pescoços; são, portanto, adjetivos qualificativos.

Contraste, por outro lado, é a propriedade de determinados adjetivos (além de outros vocábulos) de isolar determinados elementos dos demais elementos idênticos a eles ou pertencentes à mesma espécie de referentes.

12) Vocês são aqueles dois moleques deselegantes e feios?!

13) Onde se meteu aquele sargento balofo?

Apesar dos exemplos serem quase os mesmos anteriores, a função dos adjetivos mudou enormemente. Eles não servem mais apenas para qualificar os determinados, mas para estabelecer um contraste entre esses determinados e outros da mesma espécie: deselegantes e feios servem para identificar aqueles dois moleques (Cebolinha e Cascão) de todos os outros moleques, e aquele sargento (Tainha) de todos os outros sargentos; são, consequentemente, adjetivos contrastivos. 


\subsection{Adjetivos ordinais}

Adjetivos ordinais são aqueles que se referem a séries ordenadas a partir de dois extremos. Os números cardinais e ordinais, quando usados como adjetivos, e adjetivos hierárquicos, como as patentes militares, seriam adjetivos ordinais.

14) O primeiro amor nem sempre é o último amor.

15) Qual tomo o Sr. quer? Tomo um ou tomo dois? (ouvido numa banca de jornais)

16) O tenente Mironga é mais tenente que amigo.

\subsection{Modos volitivo e imprecativo}

A palavra modo é usada aqui não para designar o modo verbal, mas para indicar o elemento emotivo do discurso, a intenção do falante ou do sujeito da sentença.

Modo volitivo é o das sentenças em que aparece o elemento emotivo desejo, enquanto modo imprecativo seria o das maldições e ofensas, em que aparece o elemento emotivo ódio. Esses modos podem ser expressos por verbos (querer), advérbios (tomara), formas verbais (futuros) e, como tentarei provar, pela ordem dos vocábulos na sentença.

17) Boas férias! (modo volitivo)

18) Pafúncia é a vovozinha, seu moleque atrevido! (modo imprecativo)

\subsection{Condição}

Antes de se fazer um estudo da colocação dos adjetivos, é mister diferenciá-los do que Halliday chama condition. Condição seria uma classe de palavras outra que não o adjetivo, embora venha expressa sob a forma de um adjetivo, que imporia uma condição para a sentença pela qualificação do substantivo, à maneira das orações subordinadas adverbiais condicionais, pelas quais, geralmente, pode ser substituída.

19) Comprei um quilo de maçãs deliciosas. (adjetivo) 
20) Gosto de maçãs deliciosas. (condição; pode ser substituído por: se forem deliciosas)

Como eu não considero os adjetivos que expressam condição como adjetivos, mas sim advérbios, não os abordarei em meu trabalho. À guisa de informação, só foram encontrados exemplos de condição após o substantivo.

\subsection{Marcação}

Lyons define termos em marcados e não marcados, em que os termos não marcados expressariam o caráter mais geral que se atribui a determinado vocábulo e os termos marcados expressariam o caráter menos geral do vocábulo, a diferença. Teríamos, assim, nos pares cavalo e égua e ovelha e carneiro, os primeiros termos: cavalo e ovelha, como não marcados, e os segundos termos: égua e carneiro, como marcados.

Acredito que a marcação da diferença não só não se restringe ao léxico, como é uma das bases fundamentais da estruturação da língua portuguesa, tanto assim que certas noções, como acentuação e pontuação, tornam-se bem mais claras quando explicadas a partir do conceito de marcação da diferença. Nesse trabalho, buscarei demonstrar que a inversão na ordem dos adjetivos é um tipo de marcação.

\section{A colocação padrão do adjetivo no português}

O padrão de colocação do adjetivo no português será antes ou depois do substantivo, dependendo do tipo de adjetivo empregado. É importante notar que eu considero como adjetivos não só os ditos adjetivos, como também os numerais ordinais (adjetivos ordinais), o uso adjetival dos numerais cardinais (adjetivos numéricos) e as expressões anafóricas, quer de identidade (mesmo, próprio, semelhante, tal), quer de oposição (outro), além dos adjetivos possessivos.

\subsection{Adjetivos normalmente antepostos}

Há quatro tipos de adjetivos que são normalmente antepostos no português: os ordinais (abrangendo os numerais ordinais, adjeti- 
vos como último, derradeiro etc., e os adjetivos hierárquicos), os possessivos, os anafóricos (mesmo, próprio, tal, semelhante, outro etc.), a adjetivos que expressam um tipo de restrição, de seleção, como simples, mero, único etc.

21) Ela já esteve entre nós, quando seu primeiro filme.

22) Você sabe qual é a última moda da Terra?

23) Este disco nos chega da própria gravadora do cantor...

24) Tião Maia, o nosso "cowboy"milionário, que vive.

25) É como se você estivesse em outra cidade...

26) Foi um simples desentendimento.

27) Não derramei uma única gota.

\subsection{Adjetivos normalmente pospostos}

Como a tendência do português é pospor o adjetivo ao substantivo, serão normalmente pospostos todos os adjetivos que não se enquadrarem nas classificações anteriores. O único fato digno de nota é quanto ao uso adjetival de números cardinais, os quais, apesar de nocionalmente comportarem-se como adjetivos ordinais (marcam uma ordenação), são obrigatoriamente pospostos (para obstar a "leitura" como numeral).

28) Quero o tomo dois do Hauser. (adjetivo numérico)

29) *Eu quero o dois tomo do Hauser. (agramatical)

30) Eu quero os dois tomos do Hauser. (numeral)

\section{Inversão da ordem dos adjetivos pospostos}

Limitaremos nosso estudo dos fatores que podem influir na mudança na ordem dos adjetivos pospostos a dois tipos: fatores semânticos e fatores sintáticos, deixando de lado possíveis fatores pragmáticos. 


\subsection{Fatores semânticos}

Os fatores semânticos que predispõem à inversão da ordem dos adjetivos pospostos podem ser de três espécies: primeiro, temos a encapsulação ou inclusão de significado do adjetivo no significado do substantivo; depois, temos as variações valorativas do adjetivo, uso irônico e eufemismo, que dependem do enfoque do falante; e por último, temos as mudanças no significado do adjetivo no contexto: restrição do significado, deslocamento do significado e uso metafórico.

\subsubsection{Encapsulacão}

A primeira vez que me ocorreu a relação entre a encapsulação do significado do adjetivo no significado do substantivo como causa de anteposição do adjetivo foi durante a leitura da seguinte passagem de Y-Juca Pirama, de Gonçalves Dias:

Possas tu, descendente maldito

De uma tribo de nobres guerreiros

Implorando (a) cruéis forasteiros,

Seres presa de vis aimorés.

A anteposição do adjetivo aqui não é somente o caso de respeitar-se a rima e a métrica, mas também de manter a coerência semântica do enunciado. Uma vez que o falante é um membro da tribo que está em guerra com os aimorés, um sintagma do tipo aimorés vis seria uma tautologia, já que todo inimigo é, implicitamente, vil (dentro da visão maniqueísta do romantismo). Daí, podemos partir para uma generalização como: "toda vez que a definição do significado do adjetivo estiver contida (encapsulada) na definição do significado do substantivo, a tendência será antepor o adjetivo".

31) Você pode comprar as deliciosas iguarias de Maria Theresa Weiss...

32) Dê ao seu pai um luxuoso relógio de ouro da...

33) Os perversos piratas do capitão Gancho...

Nos exemplos acima, os adjetivos deliciosas, luxиoso e perversos estão encapsulados, respectivamente, em iguarias (reforçado pela locução adjetiva "de Maria Theresa Weiss", famosa doceira), relógio de ouro e piratas. A posposição só se justificaria se fôssemos 
opor iguarias deliciosas a iguarias não deliciosas, relógios de ouro luxuosos a relógios de ouro não luxuosos e piratas perversos a piratas não perversos.

Essa anteposição do adjetivo funcionaria, nesses casos, como uma inversão da relação determinado/substantivo e determinante/adjetivo, em que o substantivo passaria a ser, de certa forma, o "determinante" do adjetivo, indicando "entre aquilo que é delicioso, as iguarias de Maria Thereza Weiss", "entre aquilo que é luxuoso, um relógio de ouro", e "entre aquilo que é perverso, os piratas do Capitão Gancho".

Quando existe uma antítese (oposição) entre o conteúdo semântico do substantivo e o conteúdo semântico do adjetivo, ou seja, uma aparente incompatibilidade semântica (uma encapsulação inversa), a anteposição do adjetivo é praticamente obrigatória.

34) A parábola do bom ladrão é uma das mais belas da Bíblia.

35) O musical "Pobre menina rica" de Vinicius de Morais.

\subsubsection{Variações valorativas do adjetivo}

Um adjetivo pode ter seu valor enfraquecido quer pelo uso $i$ rônico que se faz dele, quer pelo seu uso como um eufemismo. Nesses casos, o falante pode usar ou não a inversão de ordem como uma marcação desse enfraquecimento.

\subsubsection{Ironia}

A anteposição do adjetivo na elocução de uma sentença irônica é apenas uma das muitas formas de se marcar uma ironia (outras são a entoação, o grau e o uso de intensificadores). Por isso, ela não é muito frequente, a não ser nos casos em que se estabelece uma antífrase entre o adjetivo e o substantivo.

36) Bela porcaria que você fez!

37) Bonito trabalho! (após o recruta Zero quase destruir o quartel Swampy). 


\subsubsection{Eufemismo}

A marcação do eufemismo pela anteposição do adjetivo não é muito comum, pois geralmente o adjetivo "tabu" é substituído por outro mais suave. A única exceção é a palavra velha, a qual nunca é usada posposta a um substantivo pessoal feminino, a menos que o falante pretenda, realmente, ofender o referente do substantivo.

38) Dona velha, feia e sandia. (cantiga de escárnio)

39) Uma velha dama de linhagem. ...

40) elegante velha senhora (corpus da professora Lemle)

Note-se que, no exemplo da professora Miriam Lemle, a posposição do adjetivo resultaria insultuosa.

41) elegante senhora velha

Apesar de eu não ter achado nenhum exemplo de posposição do adjetivo velha que não fosse pejorativo, para o adjetivo masculino velho a colocação é normalmente indiferente.

42) Meu velho amigo, que prazer em vê-lo.

43) Amigo velho, muito lhe admiro, meu chapéu lhe tiro...

\subsubsection{Mudanças no significado do adjetivo}

Um adjetivo pode ser usado num sentido especial num determinado contexto ou adquirir um sentido específico quando empregado num contexto específico. Essas mudanças no significado resultam numa restrição do significado (aí entendido também a especialização do significado), num deslocamento do significado ou num uso metafórico do adjetivo.

\subsubsection{Restrição do significado do adjetivo}

Quando um adjetivo tem várias possibilidades de leitura semântica e o contexto ou o falante exprime apenas uma dessas leituras, será normal que o adjetivo venha anteposto.

Isso foi muito notado no meu corpus com relação aos adjetivos bom, novo e velho; sempre que esses adjetivos restringiam-se às 
leituras de adequado, que passou a existir há pouco e antigo, respectivamente, eles eram antepostos.

44) Você chega em casa, põe gelo no copo, deixa cair uma boa dose de uísque,...

45) Um bom gole disso e você se sentirá novo em folha!

46) Agora, para enfrentar o frio, um novo produto.

47) Minha nova máquina de criar monstros vai fazer o maior sucesso.

48) Ao longo dos corredores e velhas celas...

49) Você ainda esta com aquela velha mania?

$\mathrm{O}$ adjetivo bom, além dessa restrição, tem outro sentido restrito de "bom em algum tipo de desempenho ou função", que é marcado pela anteposição. Por outro lado, quando ele é usado no sentido de sensual (geralmente no feminino), não é visto como uma especialização de significado, ocorrendo normalmente posposto ao substantivo, podendo-se até opor uma leitura (competente, capaz) à outra (sensual).

50) Ela é uma boa professora ou uma professora boa?

Da mesma forma, podemos opor as duas leituras de velho e novo, conforme estejam antepostos ou pospostos.

51) Você vai me apresentar a uma velha amiga ou a uma amiga velha?

52) Prefiro as mulheres novas às novas mulheres.

\subsubsection{Deslocamento do significado}

Se um adjetivo passa a ser usado num sentido deslocado do seu sentido comum, é comum sua anteposição. Assim sendo, os adjetivos longo, duro, grande, famoso e verdadeiro, quando usados nos sentidos de cansativo, árduo, magnífico, conhecido e real, respectivamente, serão antepostos.

53) O longo caminho percorrido por uma mulher em busca de si mesma,...

54) Foi um duro aprendizado, que me custou...

55) Agora, vamos ao grande ataque!

56) Vou usar a minha famosa jogada de calcanhar! 


\section{FACULDADE dE FoRMAÇÃO de PROFESSORES}

57) A casa dele é uma verdadeira mansão.

Note-se que todos esses adjetivos podem ser antepostos também em seu sentido normal, de acordo com certos fatores sintáticos que estudaremos depois, mas sua colocação geral, quando não ocorre deslocamento de sentido, é posposta.

58) Daqui até a cidade mais próxima, é um caminho longo.

59) Já comi muito pão duro.

60) Me disseram que tem peixes grandes nessa área.

61) Agora ela é uma atriz famosa, não precisa se matar.

62) Essa é a história verdadeira, se quiser que acredite!

\subsubsection{Uso metafórico do adjetivo}

O uso metafórico dos adjetivos, isto é, aquele que envolve uma comparação implícita (aí incluídos certos deslocamentos, antropomorfizações etc.) é, na maioria das vezes, anteposto ao substantivo.

63) Com todo esse barulho, como é que um pobre cão pode dormir?

64) E que duas inocentes azeitonas têm tanta caloria quanto dez folhas de alface?

\subsection{Fatores sintáticos}

Os fatores sintáticos que alteram a ordem dos adjetivos pospostos derivam ora do tipo de adjetivo empregado, do grau do adjetivo ou do tipo de sintagma nominal em que o adjetivo se inclui, além do modo da sentença.

\subsubsection{Tipo de adjetivo empregado}

Existem três tipos de adjetivos que, pelas suas características sintáticas, dificultam a anteposição do adjetivo: os adjetivos negativos, os adjetivos participiais e os adjetivos que requerem complemento nominal. 


\subsubsection{Adjetivos negativos}

Embora não chegue a se constituir numa construção agramatical, a anteposição do adjetivo negativo é geralmente artificial. Essa estranheza é muito mais sentida com relação aos adjetivos iniciados pelo prefixo não do que nos demais.

65) ... e seu sentimento não extravasado se acumulou.

66) ... e seu ( ? ) não extravasado sentimento se acumulou.

67) O túmulo do soldado desconhecido.

68) O túmulo do (!) desconhecido soldado.

69) Um homem imoral.

70) Um ( ! imoral homem,

Adjetivos negativos que adquiriram uma conotação positiva com o correr dos tempos ou que estão sendo usados num sentido deslocado, são comumente antepostos ao substantivo.

71) fazer de um simples pãozinho um banquete irresistível.

72) fazer de um simples pãozinho um irresistível banquete.

73) Uma garota incrivel.

74) Uma incrível garota.

75) Um homem infeliz.

76) O infeliz, homem.

\subsubsection{Adjetivos participiais}

Os adjetivos participiais, que tanto podem ser oriundos do particípio presente quanto do particípio passado, são preferencialmente pospostos quando mantêm seu valor de verbos.

77) estrela cadente

78) ( !) cadente estrela

79) instrumento cortante

80) (!) cortante instrumento

81) batata frita 


\section{FACULDADE de FoRMAÇÃO de PROFESSORES}

82) ( ? frita batata

83) legumes cozidos

84) ( !) cozidos legumes

No entanto, podem-se usar os adjetivos participiais antepostos se eles tiverem perdido seu valor verbal.

85) O presente trabalho versa sobre os seguintes tópicos...

86) O falecido escritor Érico Veríssimo...

\subsubsection{Adjetivos que requerem complemento nominal}

É difícil deslocar-se o adjetivo que requer complemento nominal para a esquerda e, ao mesmo tempo, manter a coerência do discurso.

87) $\mathrm{O}$ ar é um elemento essencial à vida.

88) $\mathrm{O}$ ar é um ( *) essencial elemento à vida.

89) O ar é um ( ? ) essencial à vida elemento.

90) O corpo faminto de droga entra em convulsões...

91) O (*) faminto corpo de drogas entra em convulsão.

92) O (?) faminto de drogas corpo entra em convulsões.

Embora não se possa antepor um adjetivo que necessite de um complemento nominal, pode-se antepor o adjetivo desse tipo quando o complemento nominal se refere ao sintagma nominal como um todo (complemento do adjetivo e do substantivo).

93) Esse é o momento oportuno para comprar dólares.

94) Esse é o oportuno momento para comprar dólares.

95) ...tomar as medidas necessárias para acabar com a inflação.

96) ...tomar as necessárias medidas para acabar com a inflação.

\subsubsection{Graus dos adjetivos}

Dependendo da forma como for expresso o grau dos adjetivos, a anteposição do adjetivo se verificará ou não. O grau dos adjetivos pode ser dividido em comparativos e superlativos especiais; 
comparativos e superlativos adverbializados; superlativos sintéticos; aumentativos e diminutivos.

\subsubsection{Comparativos e superlativos especiais}

Os adjetivos bom, mau, grande e pequeno têm formas especiais para o comparativo de superioridade ou superlativo relativo e para o superlativo absoluto. Estudaremos as formas do superlativo absoluto junto aos superlativos sintéticos; quanto às formas do comparativo de superioridade ou superlativo relativo, são elas, respectivamente: melhor e o melhor; pior e o pior; maior e o maior; e menor e o menor.

Existe uma relação profunda entre esses adjetivos e os artigos que antecedem o sintagma nominal: após artigo definido, o adjetivo vem geralmente anteposto e é sempre (ao menos, no meu corpus) superlativo relativo; após artigo indefinido ou quando não há artigo algum, o adjetivo vem quase sempre posposto (apenas um caso de anteposição) e é sempre comparativo de superioridade (ao menos, no meu corpus).

97) o menor garotinho que você já viu. (anúncio de TV)

98) a maior colher que você já viu. (anúncio de TV)

99) ...o melhor amigo do homem.

100) Esta é a pior peça que eu já vi .

101) Vou mudar para um apartamento menor. (do que o antigo)

102) ...o marido passa a assumir maiores responsabilidades. (do que as que tinha anteriormente)

103) Precisamos lutar por um ensino melhor. (do que o atual)

104) Existem coisas piores.(do que essas)

\subsubsection{Comparativo e superlativo adverbializados}

A expressão "comparativos e superlativos adverbializados" está sendo usada aqui para indicar adjetivos modificados por qualquer advérbio de intensidade ou advérbio de modo que expresse um aumento ou decréscimo no valor do adjetivo, o que em inglês se 


\section{FACULDADE de FoRMAÇÃO de PROFESSORES}

chama de "intensifiers", não apenas os advérbios de intensidade ou de grau mais, menos, tão, muito e pouco.

105) Sofisticação e bom gosto a um preço bem acessivel.

106) ... um homem completamente diferente.

107) ... um céu intensamente azul.

Esses são três exemplos de superlativo que não usam o advérbio muito, mas outro advérbio. Sentenças com comparativos adverbializados por outras expressões que não mais ou menos também ocorrem, embora sejam bem raras.

108) Estude com professores superiormente treinados.

109) ... os caminhos preferencialmente usados...

Notem que, apesar dos advérbios acima manterem o valor de advérbio de modo, eles são também intensificadores dos adjetivos (intensifiers). Nenhum exemplo foi encontrado, no entanto, de comparativos de igualdade com expressões outras que não tão.

O fato importante é que os comparativos e superlativos adverbializados são geralmente pospostos, sendo que nos sintagmas nominais iniciados por artigo definido serão raramente usados como superlativo absoluto (somente em contextos muito especiais) e nunca (ao menos, no nosso corpus) serão antepostos aos sintagmas nominais começados por artigo indefinido. Estudaremos a razão dessa diferença mais adiante.

110) O homem mais famoso do Brasil é o Pelé.

111) Não existe brasileiro mais famoso do que o Pelé.

112) Ele é um homem muito famoso.

113) Ele é um ( ? ) muito famoso homem.

114) Ele é ( ? ) o muito famoso homem.

115) Ele é o homem ( ! ) muito famoso. (só se justifica se for seguido por uma frase como: "de quem estávamos falando") 


\subsubsection{Superlativos sintéticos}

Superlativos sintéticos são aqueles que não necessitam de advérbio de intensidade ou de grau. Nesse tipo eu incluí, além dos superlativos terminados nos sufixos -íssimo e -imo, os superlativos de forma especial ótimo, péssimo, máximo, mínimo, ínfimo (de inferior) e supremo ou sumo (de superior).

Tanto os superlativos absolutos sintéticos usuais como os especiais têm ampla possibilidade de mudança. Diferem, isto sim, é quanto à sua colocação padrão: enquanto os superlativos sintéticos usuais são geralmente pospostos (apenas uma exceção no corpus), os superlativos especiais são preferencialmente antepostos (cerca de $70 \%$ dos exemplos no corpus).

116) É uma ótima ideia.

117) É uma ideia ótima.

118) Compre nossos pães fresquíssimos!

119) Compre nossos fresquíssimos pães!

Os adjetivos que têm significado superlativo (podem ser descritos por outro adjetivo no grau superlativo) seguem o mesmo padrão dos superlativos especiais.

120) ... com um acabamento excelente.

121) ... com um excelente acabamento.

\subsubsection{Aumentativo e diminutivo}

Quando se aplica os graus aumentativo e diminutivo ao adjetivo (linguagem coloquial), este é anteposto sempre.

122) ...uma caverna escurinha e quentinha...

123) ...uma ( ? ) escurinha e quentinha caverna...

124) Ponto Frio bonzão

125) ( ? ) bonzão Ponto Frio

126) mulher boazuda

127) ( !) boazuda mulher 


\section{FACULDADE de FoRMAÇÃO de PROFESSORES}

\subsubsection{Tipos de sintagma nominal}

Como vimos anteriormente com relação aos superlativos relativos e comparativos especiais, o tipo de sintagma nominal pode influir na colocação do adjetivo. Influirão na colocação do adjetivo os seguintes tipos de sintagma nominal: definido e indefinido, contrastivo e complexo.

\subsubsection{Sintagmas definidos e indefinidos}

Os sintagmas se dividem em definidos e indefinidos, conforme se refiram ou não a um elemento ou classe de elementos específicos. Os sintagmas indefinidos são aqueles constituídos somente pelo substantivo ou pelo substantivo precedidos por numeral, artigo indefinido ou pronome indefinido, e determinam a posposição do adjetivo como padrão de ordenação.

128) um chá quente

129) um (?) quente chá

130) um homem muito diferente

131) um (?) muito diferente homem

132) Estou procurando uma roupa mais barata.

133) Estou procurando uma (?) mais barata roupa.

134) um apartamento menor

135) um (?) menor apartamento

Algumas vezes, porém, a mudança na ordem do adjetivo no sintagma é possível com sintagmas indefinidos, como podemos ver abaixo.

136) Estou esperando uma oportunidade melhor.

137) Estou esperando uma melhor oportunidade.

138) Ele é um homem bom.

139) Ele é um bom homem.

Os sintagmas definidos, por seu turno, são aqueles precedidos por artigo definido ou por pronomes demonstrativos; os substantivos próprios; e os substantivos que designam uma coisa singular (ex: lu- 
a) e se subdividem em parcialmente definidos (precedidos por artigo ou pronome) e totalmente definidos (próprios e singulares).

Os sintagmas parcialmente definidos determinarão uma possibilidade maior de mudança na posição do adjetivo, embora alguns adjetivos só admitam a posição posposta.

140) Esses homens maravilhosos e suas máquinas voadoras.

141) Esses maravilhosos homens e suas máquinas voadoras.

142) O melhor café do mundo é o café brasileiro.

143) O café melhor do mundo é o (?) brasileiro café.

Os sintagmas totalmente definidos, ao contrário, impõem a anteposição do adjetivo, a não ser nos sintagmas contrastivos, que estudaremos na próxima seção.

144) O falecido escritor Veríssimo

145) O supermilionário J. F. L. de Moraes

\subsubsection{Sintagmas contrastivos}

De todos os fatores que influenciam a colocação dos adjetivos, o contraste é o mais importante. Contraste, aqui, designa a oposição de um elemento (ou classe de elementos) aos outros elementos (ou classes de elementos) designados pela mesma palavra (ou expressão). Sua importância para a ordenação do adjetivo decorre do fato de ele anular qualquer outro fator que determinaria essa ordenação. Os sintagmas contrastivos têm sempre o adjetivo posposto, não importa seu tipo.

Essa colocação obrigatória vai acarretar, por oposição, a anteposição dos adjetivos que são apenas qualificativos.

146) É uma boa piada. (qualificativo: não existe uma oposição implícita com as piadas não boas)

147) Ué! Onde estão as telhas boas? (contrastivo: existe uma oposição implícita com as telhas não boas)

Um tipo de adjetivo que quase sempre vem anteposto, embora não seja do tipo normalmente anteposto, são os adjetivos de profissão, que adotam essa posição por geralmente ocorrerem em sintag- 


\section{FACULDADE DE FORMAÇÃo dE PROFESSORES}

mas totalmente definidos. Quando ocorre em sintagmas contrastivos, no entanto, vem sempre posposto.

148) foi criado por mãe abandonada pelo marido chofer de caminhão...

149) o Veríssimo chargista, não o Veríssimo escritor

150) A Dolores sofrida, que luta para viver e sobreviver.

\subsubsection{Sintagmas complexos}

Sintagmas complexos é o nome utilizado neste trabalho para designar aqueles sintagmas constituídos de substantivo + locução. Tais sintagmas terão o adjetivo anteposposto ou posposto conforme seja necessário para evitar ambiguidades.

151) doce calda de ameixa (a calda que é doce)

152) calda de ameixa preta (a ameixa que é preta)

Mesmo em contextos onde não há possibilidade de ambiguidade, o adjetivo pode vir anteposto para o sintagma não ficar pesado (muita distância entre o determinado e o determinante adjetival).

153) As novas tendências das confecções europeias

154) As tendências das confecções europeias novas (!)

155) um novo produto à base de algas marinhas

156) um produto à base de algas marinhas novo (?)

\subsubsection{Modos da sentença}

Os modos volitivo (desejo) e imprecativo (ódio) funcionam de maneira oposta quanto à colocação dos adjetivos normalmente pospostos. $\mathrm{O}$ modo volitivo determina uma posição anteposta do adjetivo, talvez porque quando se deseja algo para alguém, se elimine do pensamento a ideia de contraste.

157) Boa tarde!

158) Feliz Natal!

O modo imprecativo, ao contrário, determina a posposição do adjetivo, mesmo quando este está encapsulado no substantivo, talvez 
porque, nesses casos, sempre pensemos no contraste, que a pessoa ou coisa podia ser de outra maneira.

159) Assassinos miseráveis!

160) Piranha safada!

Tanto o sentido de miseráveis quanto o de safada estão encapsulados nos significados de assassinos e piranha, mas por as sentenças estarem no modo imprecativo, eles vêm pospostos ao substantivo.

Isso não significa, no entanto, que não possam ocorrer adjetivos antepostos no modo imprecativo, mas essa anteposição do adjetivo geralmente provoca certo grau de estranheza.

161) (!) Miseráveis assassinos!

162) (?) Safada piranha!

\section{Inversão da ordem dos adjetivos antepostos}

Existem somente duas causas para a inversão da ordem dos adjetivos normalmente antepostos: a mudança semântica e o contraste. Devido ao fato de tais adjetivos não serem qualificativos, fatores como encapsulação, eufemismo, ironia e modos parecem não influenciar sua colocação, assim como os fatores sintáticos, que não provocam deslocamento pelo fato de esses adjetivos virem antepostos. Quanto ao fato de os sintagmas indefinidos só aceitarem adjetivos possessivos pospostos, isto é explicado pelo uso contrastivo do adjetivo e não pelo fato de o sintagma ser indefinido.

\subsection{Mudança semântica}

A mudança semântica que acarreta a posposição dos adjetivos normalmente antepostos é muito mais profunda do que aquela que altera a ordem dos adjetivos normalmente pospostos; pode-se mesmo dizer que, em determinados casos, temos dois adjetivos diferentes com a mesma forma.

162) Você sabe qual é a última moda da Terra?

163) Cientistas tentam descobrir a causa última da vida. 


\section{FACULDADE DE FoRMAÇÃo de PROFESSORES}

164) O rio é o mesmo rio, mas não é o mesmo rio. (Lao Tzé)

165) A razão mesma da separação, eu não sei.

Note-se, nos exemplos acima, como os adjetivos última e mesmo, mesma mudam de significado de acordo com a posição que ocupam: antepostos significam, respectivamente, final ou mais recente e igual ao já citado, pospostos significam fundamental e real.

\subsection{Contraste}

O contraste é a causa mais comum de posposição do adjetivo normalmente anteposto e atinge tanto os ordinais como os anafóricos e possessivos.

166) A rainha até mandou buscar nosso irmãozinho para uma entrevista particular.(não contrastivo: anteposto)

167) Não importa! O que interessa é que você é um irmãozinho nosso. (contrastivo: posposto)

168) ... o único cantor do mundo... (não contrastivo: anteposto)

169) Filho único... (contrastivo: posposto)

170) Juca Chaves com gravadora própria (contrastivo: posposto)

171) ... nos chega através de sua própria gravadora (não contrastivo: anteposto)

172) Dom Pedro I (primeiro) (contrastivo: posposto)

173) Os primeiros habitantes... (não contrastivo: anteposto)

Notem que, embora os adjetivos antepostos sejam geralmente definidores do sintagma, o que é um tipo atenuado de contraste, eles só serão pospostos quando contrastivos (totalmente definidores).

\section{Conclusão}

De acordo com o que vimos ate agora, temos o seguinte esquema de ordenação do adjetivo em relação ao substantivo no português:

a) Serão pospostos os adjetivos constituídos por um número cardinal tornado em adjetivo; 
b) Serão pospostos os adjetivos qualificativos e antepostos os adjetivos não qualificativos, a menos que algum fator semântico ou sintático interfira;

c) Serão pospostos os adjetivos (qualificativos ou não) que expressem contraste;

d) Serão antepostos os adjetivos qualificativos e pospostos os adjetivos não qualificativos quando ocorrer uma mudança de significado no adjetivo;

e) Serão antepostos os adjetivos qualificativos encapsulados no substantivo;

f) Serão pospostos os comparativos e antepostos os superlativos;

g) Serão antepostos os adjetivos em sentenças volitivas;

h) Serão pospostos os adjetivos em sentenças imprecativas.

É importante notar, todavia, que embora expressem tendências razoavelmente gerais, todos esses fatores determinantes da ordem dos adjetivos têm exceção.

\section{REFERÊNCIAS BIBLIOGRÁFICAS}

A PANTERA cor-de-rosa, 59. São Paulo, abril, junho 1983. A PATADA, 144. São Paulo, Abril, julho 1983.

ALMANAQUE da turma da Mônica, 18. São Paulo, Abril, junho 1983.

ALMANAQUE DO CASCÃO, 6. São Paulo, Abril, abril 1983.

ALMANAQUE ZERO, 19. Rio de Janeiro: Rio Gráfica, julho 1983.

CLÁUDIA, 262. São Paulo, Abril, julho 1983.

HALLIDAY, M. A. K. Notes on transitivity and theme in English, part 1. Journal of Linguistics, London, 2(1), p. 37-81. 


\section{FACULDADE de FoRMAÇÃO de PROFESSORES}

LEMLE, Míriam. A ordem dos adjetivos no sintagma nominal inglês: implicações para a teoria gramatical. Comunicação apresentada no III Encontro Nacional de Linguística, PUC/RJ, 1979.

LYONS, John. Semantics. Cambridge: Cambridge University Press, 1979, v. 1, p. 261-335.

PONTES, Eunice. Topicalização e deslocamento para a esquerda. Comunicação apresentada no V Encontro Nacional de Linguística, PUC/RJ, 1981.

ULLMANN, Stephen. Semântica: uma introdução à ciência do significado. Lisboa: Fundação Calouste Gulbenkian, p. 401-491. 